\title{
Inhibition of Phenylethanolamine-N-Methyltransferase and Brain-Stimulated Reward
}

\author{
R. J. KATZ and B. J. CARROLL \\ Mental Health Research Institute, Department of Psychiatry, University of Michigan Medical Center, \\ Ann Arbor, Michigan 48109, U.S.A.
}

Abstract. Three centrally active inhibitors of phenylethanolamine-N-methyl transferase (PNMT; E.C. 2.1.1.28), the terminal enzyme for epinephrine biosynthesis in the brain, produced dose-related decreases in rates of responding for rewarding brain stimulation in adult male rats. Decreases occurred at dosages that did not produce measurable neurologic impairment. This suggests a possible role for central epinephrine-containing neurons in the maintenance of reward-mediated behaviors.

Key words: Brain stimulation - Epinephrine PNMT - Reward

The involvement of central catecholamine-(CA-)containing neurons in the mediation of reward has been established through a variety of anatomical, pharmacological, and neurochemical techniques. Anatomical findings, for example, suggest a considerable degree of overlap between brain sites supporting intracranial selfstimulation and CA-containing cell bodies or fiber bundles (Crow, 1972a, b; German and Bowden, 1974). Moreover, pharmacological manipulation of these sites suggests that drugs potentiating the release of $\mathrm{CA}$ lower threshold current levels that will maintain operant responding for central stimulation and increase rates of response for a given intensity of current. As might be expected, CA-specific blockers, biosynthesis inhibitors, and neurotoxins produce opposite effects (e.g., Rolls, 1975; Stein, 1968, 1975; Wise et al., 1973). Additional support for CA control of central reward comes from the relationship of self-stimulation and central neurochemical changes; i.e., self-stimulation results in potentiated CA release and increased CA biosynthesis (e.g., Arbuthnott et al., 1971; Miliaressis et al., 1975).
Heretofore, most studies of catecholaminergic involvement in self stimulation and reward have focused on noradrenergic (NA) or dopaminergic (DA) systems, since these were the only two CA neurotransmitters believed to exist in the brain (Fuxe et al., 1970; Ungerstedt, 1971). Recently, however, a third CA, epinephrine (Epi), has also been identified and localized in the brains of mammals and other species, and this suggests another neurotransmitter that may be involved in the mediation of reward. Evidence for Epi involvement comes from three sources. On the one hand, Epi-containing cells are known to innervate a number of brain sites that support self-stimulation, e.g., the locus coeruleus and a variety of hypothalamic and limbic system sites (Hokfelt et al., 1974; Saavedra et al., 1974; Lew et al., 1976). At least one report suggests that self-stimulation may also be obtained from Epi cell bodies (Carter and Phillips, 1975; note also O'Donohue and Hagamen, 1967, Figs. 3 and 4). Furthermore, most pharmacological manipulations affecting NA and DA biosynthesis have necessarily also altered CNS Epi stores since NA and DA are the neurochemical precursors of Epi synthesis, and therefore the reported behavioral changes may be a function of either the former neurotransmitters or Epi. Finally, intraventricular administration of exogenous Epi increases ongoing rates of operant responding for medial forebrain bundle self-stimulation (Hasegawa, 1975).

Until recently no drugs were available to test specifically for the behavioral effects of inhibiting Epi biosynthesis. Several inhibitors of PNMT have now been developed, however, and we have studied their effects on ICS. The drugs we have used are Lilly DCMB; 2,3 dichloro-a-methylbenzylamine: SKF 7698; 3 methyl-1,2,3,4 tetrahydro (1)benzothieno-(3,2-c) pyridine hydrochloride: SKF 64139; 7,8 dichloro-1,2,3,4 tetrahydroisoquinoline $\mathrm{HCl}$ (Fuller et al., 1973; Lew et al., 1976; Pendelton et al., 1976). 


\section{MATERIALS AND METHODS}

The subject pool consisted of 16 adult male Sprague-Dawley rats weighing 300-475 g obtained from a local supplier (Charles River Farms, Portage, Michigan). They were maintained with food (Wayne lab blocks) and water continuously available, with automatically programmed day/night cycles of $12 \mathrm{~h}$ each (light onset and offset were at 7 and $19 \mathrm{~h}$ ). Each rat was used for a total of $6-10$ drug and vehicle tests of 14-h duration each. Five rats were used to test each drug dosage and a control group of 5 rats injected with $0.9 \%$ sterile saline vehicle was run concomitantly with each drug injection. Because of the limited solubility of SKF 7698, both drug and control injections for this compound utilized a $1 \%$ Tween- 80 in saline vehicle. All drugs were administered by i.p. injection and dosages were based on the established CNS neurochemistry of each compound. In each case the maximum dose used for behavioral testing had previously been shown to produce $90 \%$ or greater inhibition of central PNMT (Lew et al., 1976). A 72-h drug-free recovery period preceded a given drug injection. Recovery from drug effects was virtually complete at $48 \mathrm{~h}$ (i.e., rates recovered to $90 \%$ or more in all cases).

The self-stimulation task of Wolf et al. (1973) was used for all testing. Surgical procedures, brain sites, stimulation parameters, apparatus, and training procedures were identical with published reports. In the present experiments the displacement of a $14 \mathrm{~cm}$ $\times 16 \mathrm{~cm}$ steel plate located $14 \mathrm{~cm}$ from the cage floor resulted in the delivery of monopolar brain stimulation through a skull-mounted wire brushing. Stimulation consisted of a $0.3 \mathrm{~s}$ train of $60 \mathrm{cps}$ sinusoidal current. Final values of current ranged from $50-200 \mu \mathrm{A}$. At the close of the experiment all subjects were sacrificed with an overdose of sodium pentobarbital (Nembutal) and perfused initially with $0.9 \%$ saline and subsequently with formal-saline-acetic acid fixing solution. Brains were then sectioned and stained with cresyl violet for standard histological examination (Luna, 1960).

In addition to self-stimulation, subjects were also tested under the same drug dosages for possible neurological impairment (e.g., ataxia, loss of coordination, sedation). Neurological testing involved placing individual subjects upon a horizontal $1 \mathrm{~m}^{2}$ wire grid located $1 \mathrm{~m}$ from the floor during the fourth hour after injection. The grid was rotated $90^{\circ}$ until it was perpendicular to the floor, and rats were considered intact if they remained upon the grid or attempted to climb to its upper surface. Rats that fell from the grid or slid toward its lower surface were considered impaired.

\section{RESULTS}

Initial baseline rates of response (to the nearest 100 responses) for the three drugs were 2500 responses $/ h$ (range $500-3700$ ), 2900 responses/h (range $800-$ 4100 ) and 2100 responses $/ \mathrm{h}$ (range $500-3000$ ) for DCMB, 64139, and 7698 respectively. After drug treatment the rates declined within $1 \mathrm{~h}$, and reductions persisted throughout the session. Since individual subjects showed widely differing response baselines, scores were percentage transformed to allow equal weighting of all change. The effects of drug and vehicle injection on self-stimulation are presented in Figure 1. Injection of vehicle across sessions produced only minor and inconsistent changes in rate, while each of the three drugs clearly reduced self-stimulation in a dose-related manner. Neurological impairment was observed only at the highest dose of each drug tested, while significant reductions in response rates were found considerably

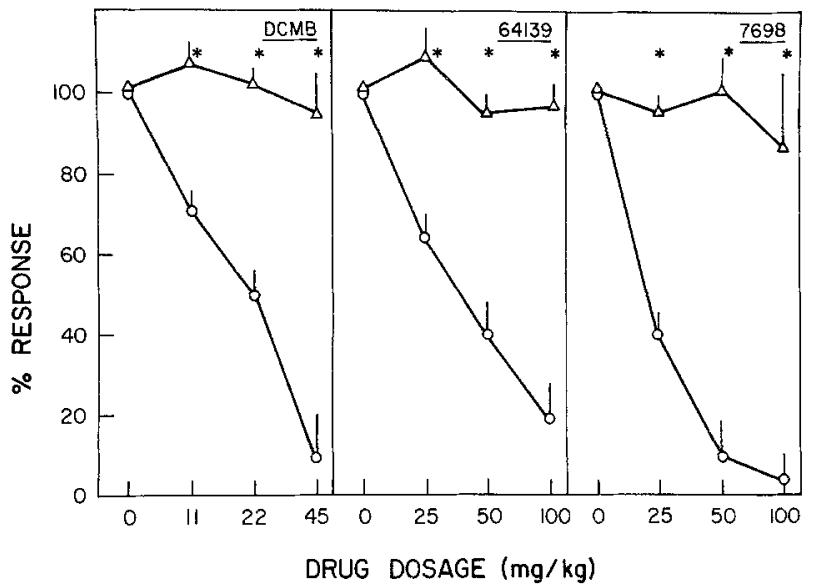

Fig. 1. Effect of three epinephrine biosynthesis inhibitors on selfstimulation. All scores for 14 -h session given as mean percentages of vehicle (i.e., $0 \mathrm{mg} / \mathrm{kg}$ ) and percent SEs. $* P<0.01$ in relation to vehicle-injected control; $t$-test for independent samples (Dixon and Massey, 1969)

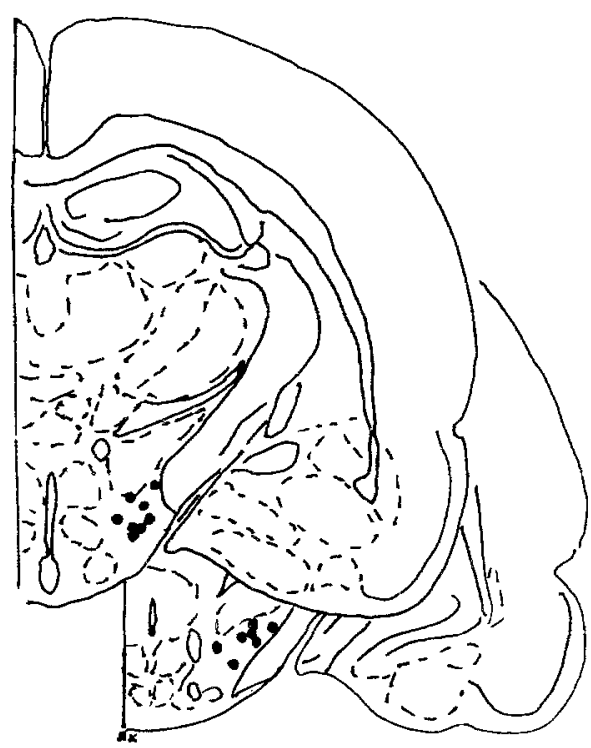

Fig. 2. Composite histology of self-stimulation sites (figures redrawn after De Groot, 1959). Sections are $-4.6,-4.2 \mathrm{~A}$ (Figs. 17, 18)

below these levels. Rate reductions therefore were apparently not a function of motor impairment or sedation. Rate reductions due to sedation are also unlikely since DCMB, which effectively inhibits selfstimulation, reportedly has direct central stimulant effects (Fuller et al., 1973). Final histologic examination revealed all sites to be located in the caudal medial forebrain bundle at the level of the posterior hypothalamus (Fig. 2).

\section{DISCUSSION}

Previous reports have indicated rate-enchancing effects for exogenous Epi administration (Hasegawa, 1975). A 
role for adrenergic neurons in self-stimulation is also established by the finding of self-stimulation from Epi cell bodies and axons (Carter and Phillips, 1975; O'Donohue and Hagamen, 1967). It might be noted in this regard that not all attempts to find self-stimulation in these areas have been successful (Clavier and Routtenberg, 1974; Routtenberg, 1975). Other studies, however, have pointed to robust self-stimulation along the postulated trajectory of Epi paths (Ritter and Stein, 1974; also see above). Stimulation parameters may be one cause of this discrepancy (Carter and Phillips, 1975). Nontheless, self-stimulation from cell bodies and fibers remains an important source of supporting evidence for the present thesis.

Previous demonstrations of adrenergic involvement in brain stimulation have largely relied on anatomical evidence. Our studies also indicate a role for adrenaline based on selective pharmacological disruptions of selfstimulation. Since the pharmacological effects are postulated to be adrenaline-specific, the effects of the drugs employed on other neurochemical systems should, clearly, also be taken into account. It might be noted that SKF 64139 may have side effects that render interpretation of this drug difficult. Behaviorally effective dosages of 64139 may increase serotonin (Khalsa et al., 1976) as transmitter, which may itself have inhibitory effects on reward (e.g., Katz and Carroll, 1977). On the other hand, the remaining two drugs are not known to have this effect, and all three behavioral patterns, are quite similar. We have also observed reductions in self-stimulation with yohimbine, a blocker of adrenaline-sensitive adenyl cyclase (Katz and Carroll, unpublished data), a serotonin antagonist. This finding suggests that while serotonegic activation is an important factor in the control of reward it is probably not the cause of the present results.

The present findings may be taken as a preliminary extension of the catecholamine theory of reward to a third neurotransmitter. This extension may help to explain previous reports that appeared to be independent of NE or DA (viz. Routtenberg, 1975).

Acknowledgements. This research was supported by Grant 07417 from the National Institute of Mental Health to the first author. We are grateful to Drs. Ray Fuller of the Lilly Research Laboratories and Robert Pendleton of Smith, Kline and French Laboratories for their generous donations of drugs and advice, as well as to G. Baldrighi, R. Derman, and L. Leibler for their expert technical assistance.

\section{REFERENCES}

Arbuthnott, G., Fuxe, K., Ungerstedt, U.: Central catecholamine turnover and self-stimulation behavior. Brain Res. 27, 406-413 (1971)

Carter, D. A., Phillips, A. G.: Intracranial self stimulation at sites in the dorsal medulla oblongata. Brain Res. 94, 155-160 (1975)
Clavier, R. M., Routtenberg, A.: Ascending monoamine-containing fiber pathways related to intracranial self stimulation: histochemical fluorescence study. Brain Res. 72, 25-40 (1974)

Crow, T. J.: Catecholamine-containing neurones and electrical selfstimulation. I. A review of some data. Psychol. Med. 2, 414-421 (1972a)

Crow, T.J.: A map of the rat mesencephalon for electrical selfstimulation. Brain Res. 36, 265-273 (1972 b)

De Groot, J.: The rat forebrain in stereotaxic coordinates. Veh Kon Ned Akadem B. Naturkund 52, 1-40 (1959)

Dixon, W. J., Massey, F. J.: Introduction to statistical analysis, 3rd ed. New York: McGraw-Hill 1969

Fuller, R., Roush, B. W., Snoddy, H. D., Molloy, B. B.: Inhibition of phenylethanolamine-N-methyltransferase by benzylamines. II. In vitro and in vivo studies with 2,3-dichloro- $\alpha$-methylbenzylamine. J. Med. Chem. 16, 106-109 (1973)

Fuxe, K., Hokfelt, T., Ungerstedt, U.: Morphological and functional aspects of central monoamine neurons. Int. Rev. Neurobiol. 13, $93-121(1970)$

German, D. C., Bowden, D. M.: Catecholamine systems as the neural substrate for intracranial self-stimulation. Brain Res. 73, 381$410(1974)$

Hasegawa, K.: Changes in the self-stimulation behavior by intraventricular injection of epinephrine, norepinephrine, isoproterenol and dopamine. Jpn. J. Pharmacol. 25, 616-619 (1975)

Hokfelt, T., Fuxe, K., Goldstein, M., Johansson, O.: Immunohistochemical evidence for the existence of adrenaline neurons in the rat brain. Brain Res. 66, 235-351 (1974)

Katz, R. J., Carroll, B. J.: Intracranial reward after Lilly 110140 (fluoxetine $\mathrm{HCl}$ ) : evidence for an inhibitory role for serotonin. Psychopharmacology 51, 189-193 (1977)

Khalsa, J. H., Gessner, G., Sawyer, J., Sarau, H., Pendleton, R. G. : Inhibitory effects of SKF 64139 on phenylethanolamine-Nmethyltransferase in rat brain. Pharmacologist 18, 209 (1976)

Lew, J. Y., Miyamoto, T., Goldstein, M.: Inhibition of PNMT activity in the adrenal glands and brain stem of the rat. Biochem. Pharmacol. 25, 1433-1434 (1976)

Luna, L. G. : Manual of histological staining methods of the armed forces institute of pathology. New York: MeGraw-Hill 1960

Miliaressis, E., Thoa, N. B., Tizabi, Y., Jacobowitz, D. M. : Catecholamine concentration of discrete brain areas following self stimulation in the ventromedial tegmentum of the cat. Brain Res. 100, 192-197 (1975)

O'Donohue, N. F., Hagamen, W. D.: A map of the cat brain for regions produciag self stimulation and unilateral inattention. Brain Res. 5, 289-305 (1967)

Pendleton, R. G., Kaiser, C., Gessner, G.: Studies on adrenal phenylethanolamine- $\mathrm{N}$-methyltransferase with SKF 64139 -a selective inhibitor. J. Pharmacol Exp. Ther. 197, 623-532 (1976)

Ritter, S., Stein, L. : Self-stimulation in the mesencephalic trajectory of the ventral noradrenergic bundle. Brain Res. 81, 145-157 (1974)

Rolls, E. T.: The brain and reward, pp. 73-89. Elmsford, New York: Pergamon 1975

Routtenberg, A.: Intracranial self stimulation pathways as substrate for memory consolidation. In: Nebraska symposium on motivation, J.R. Cole and T. B. Sonderegger, eds, pp. 161-183. Lincoln: University of Nebraska Press 1975

Saavedra, J. M., Palkovits, M., Brownstein, M. J., Axelrod, J.: Localization of phenylethanolamine- $\mathrm{N}$-methyltransferase in the rat brain nuclei. Nature (Lond.) 248, 695 (1974)

Stein, L.: Chemistry of reward and punishment. In: Psychopharmacology: a review of progress, $1957-1967$, D. H. Efron, ed., pp. 106-123. Washington D.C.: U.S. Goverment Printing Office 1968

Stein, L.: Norepinephrine reward pathways, role in self stimulation, memory consolidation, and schizophrenia. In: Nebraska sym- 
posium on motivation, J. K. Cole and T. B. Sonderegger, eds., pp. 113-161. Lincoln: University of Nebraska Press 1975

Ungerstedt, U.: Stereotaxic mapping of monoamine pathways in the rat brain. Acta Physiol. Scand. [Suppl. 367] 82, 1-48 (1971)

Wise, C. D., Berger, B. D., Stein, L.: Evidence of $\alpha$-noradrenergic reward receptors and serotonergic punishment receptors in the rat brain. Biol. Psychiatry 6, 3-22 (1973)
Wolf, G., DiCara, L., Simpson, W.: The contact method: a simple technique for electrical self stimulation without external leads. Physiol. Behav. 11, $721-764$ (1973)

Received April 11, 1977; Final Version July 19, 1977 